\title{
On the Same Skywalk in a Time of Pandemic: How a vulnerable group copes with the new conditions in Hong Kong
}

\author{
Caterina Villani, Gianni Talamini, Zhijian Hu \\ Department of Architecture and Civil Engineering, City University of Hong Kong, Tat Chee \\ Avenue, Kowloon, Hong Kong SAR, China \\ cvillani2-c@my.cityu.edu.hk, gianntal@cityu.edu.hk, zhijianhu2-c@my.cityu.edu.hk
}

Tel: +85262244234

\begin{abstract}
The public space plays a crucial role in providing adequate infrastructure for vulnerable social groups in the context of high-density urban Asia. In this study, a well-known elevated pedestrian network in Hong Kong emerges as a revelatory case for the comparative analysis of the pattern of stationary uses before and after the COVID-19 pandemic out-break. Findings reveal a significant decrease (-20 $\%$ ) in the total number of users and a shift in the pattern of activities, comprising a significant shrinkage of socially oriented uses and a vast increase of individual behaviors. This study advocates a responsive policymaking that considers the peculiar post-outbreak needs of migrant workers in Hong Kong and in high-density urban Asia
\end{abstract}

Keywords: Covid-19; public space; migrant domestic workers; behavioural mapping

eISSN 2514-751X @ 2020 The Authors. Published for AMER ABRA cE-Bs by e-International Publishing House, Ltd., UK. This is an open access article under the CC BY-NC-ND license (http://creativecommons.org/licenses/bync-nd/4.0/). Peer-review under responsibility of AMER (Association of Malaysian Environment-Behaviour Researchers), ABRA (Association of Behavioural Researchers on Asians / Africans / Arabians) and cE-Bs (Centre for Environment-Behaviour Studies), Faculty of Architecture, Planning \& Surveying, Universiti Teknologi MARA, Malaysia.

DOI: https://doi.org/10.21834/ajebs.v5i17.374 


\subsection{Introduction}

Since COVID-19, strategic policy measures restrict mobility patterns, implement social distancing (SD), enforce protective measures (PM) and limit the access to public space (PS) in several cities worldwide. In some cases, the above-mentioned restrictions impacted significantly on vulnerable social groups (Wray et al., 2020), such as women, children, elderly, temporary workers, ethnic minorities and migrants. Because of precarious living and economic conditions, migrant populations may encounter more barriers in respecting $\mathrm{SD}$, hygiene measures, and accessing health services and information in host countries (Castillo and Amoah, 2020; Liem et al., 2020). Concurrently, among these vulnerable populations, social isolation may have mental health repercussions, particularly in highdensity settings with limited PS (Nobajas et al., 2020; Pouso et al., 2020; Samuelsson et al., 2020; Zhang, 2020; Zordan et al., 2019).

While the pandemic has overturned established behaviours in PS, it is still unclear how it will affect the use of PS once some restrictions will be lifted (Salama, 2020). While few studies forecast that a fundamental shift in the patterns of PS use may be possible, it is far more anticipated an impact on the vulnerable populations (Wade, 2020) and their access to and use of PS (Honey-Rosés et al., 2020). At the time of writing this article, there is very limited empirical research providing evidence on the changes in PS use by vulnerable migrant urban populations, as the migrant domestic workers (MDWs), during SD relaxation periods. This evidence may provide insights for contingency PS planning and countermeasures for offsetting future needs and risks of vulnerable populations (Lai et al., 2020).

This study was set in the context of Hong Kong aiming at representing high-density environments' post-outbreak scenario. By the end of June 2020, the city was undergoing a lifting phase under the suppress and lift disease prevention strategy that allowed social distancing measures relaxation (HKSAR, 2020). In these settings, for the MDWs -one lowincome group present in several global Asian cities-PS is often the only recreational open space for socially-oriented activities. PS can also provide relief from inadequate living settings and weekly work-related fatigue and isolation (Villani et al., 2019; Villani and Talamini, 2020, 2021). This paper -focusing on the use of the elevated pedestrian network (EPN)- investigates the use of PS. Specifically, we use the selected SD relaxation phase to explore the frequency and the spatiotemporal patterns of recreational PS use. The paper is organized as follows: aim and objectives; literature review concerning post-pandemic changes in PS use; study area; methods and findings. The discussion and conclusion sections compare the current findings with the pre-pandemic period and finally delineate the need for further studies.

\subsection{Aim and Objectives}

This article aims to analyze how the COVID-19 prevention measures, including SD and PM, affect the MDWs' recreational use of PS during the SD relaxation period in the EPN of Mong Kok, Hong Kong. The objectives of the study are set as follows:

1) To analyze the pattern and diversity of activities; 
2) To investigate location-related and activity-related and potentially hazardous contacts;

3) To measure the presence of PM, size and distance between groups of people.

\subsection{Literature Review}

Because of the changing nature of COVID-19 pandemic, it is still difficult to have a broad picture of the projected impacts on the use of PS. A recent overview of early research on COVID-19's effects highlights that the socio-economic impacts are still under-investigated (Sharifi and Khavarian-Garmsir, 2020). Historically, pandemics disproportionately impacted minorities due to pre-existing structural inequalities (idem). COVID-19 pandemic exposed underlying difficult living and working conditions of groups on the margins and made it clear that some groups suffer disproportionately over others. The pandemic hardly hit black and Latino communities in New York, as they are twice as likely to die from COVID-19 (Wade, 2020). In Asian cities COVID-19 disproportionately impacted migrant workers (Choudhari, 2020; Koh, 2020), which are suffering from unsatisfactory living and working conditions and concomitant adverse occupational situation.

Pandemics have been related to drops in levels of mental health and well-being, particularly, limited social contact is highly associated with negative psychological outcomes (Wang et al., 2020). During the COVID-19 pandemic, empirical evidence showed that social connectedness seems to play a crucial role in psychological well-being (Sun et al., 2020), thus the importance of staying socially connected whilst respecting SD measures. Nevertheless, practicing physical distancing might be challenging in highdensity PS-scarce environments, as in Asian cities (Wang et al., 2018). In these contexts, some public spaces -although residual, transitory and contested in nature- represented long-established setting for low-income groups' uses and social interactions before COVID19 pandemic (Elsheshtawy, 2020; Martinez and Masron, 2020; Ostertag, 2016; Villani and Talamini, 2021).

Research addressing the impacts of COVID-19 on social interactions is critically needed (Honey-Rosés et al., 2020). At the same time, there is a lack of empirical evidence about the impact of SD measures on vulnerable urban populations' use of PS. At the time of writing, significant research indicates that the pandemic has been aggravating preexisting inequalities, including the differential access to PS (Anguelovski et al., 2020). Notable research framed the possible scenario of COVID-19 impact on the future PS and connected dynamics. Honey-Rosés et al. (2020) project that the COVID-19 impacts will include changes in:

1) The number of users

2) The temporal patterns of use

3) The variety of uses and activities

4) Use of face masks

5) The average group sizes

In the Post-COVID city, the total use of PS is expected to change, specifically fewer people might be observed in PS. This drop will have repercussions also on how PS data 
will be gathered. The temporal patterns of PS occupation are expected to be similarly affected: peak hours will probably be avoided in retail, parks and public transport use, as $\mathrm{SD}$ is expected to be more difficult in these locations and periods. For what concerns the possible PS's use change, shopping and socializing (particularly informal social interactions), are most likely to be impacted by COVID-19. The first activity may be largely replaced by online retail. The informal social interactions among strangers in public space are expected to be limited, owing to the fear of contracting or spreading the virus. Widespread use of masks is likely to be a characteristic of public space users during the post-pandemic period. Face mask use is far more prevalent and socially accepted in Asia compared to the US (Eikenberry et al., 2020). Finally, a general aversion to large crowds may be possible. Revisiting past public life studies considering average group size in public may indicate a considerable shift (Honey-Rosés et al., 2020).

The present article attempts to fill the above-mentioned research gaps, by focusing on the changes in the use of public space by a Hong Kong's disadvantaged social group during a COVID-19 SD relaxation period. It aims to do so examining the use of one segment of EPN in Mong Kok area in Kowloon and comparing it with the pre-pandemic evidence. This space has been previously studied as hosting stationary activities performed primarily by MDWs engaging in conversation, food preparation, and food consumption (Villani and Talamini, 2019, 2020). The observed behaviors were mainly clustering near incidental sitting areas (near railings) and informal food-production areas (idem).

\subsection{Methodology}

The study area is located in Hong Kong, which is internationally recognized as one of the densest cities worldwide with limited per-capita urban PS availability. Hong Kong's urban condition may reveal significant for many hi-density Asian cities in which the informal use of PS is a matter of necessity rather than choice (Talamini and Pires Ferreira, 2019; Wang et al., 2018). The city was hit early by the pandemic and announced the first work from home recommendation and closure of public facilities (museums, libraries, sports centers) by late January 2020. Before the pandemic, the PS of EPN was observed to be an established setting for large gatherings of MDW groups -mainly young women from Southeast Asia- on Sunday, which is the typical stipulated day off (Villani and Talamini, 2020; Wang, 2020). The EPN, located in the dense and PS-scarce urban district of Mong Kok, it is set as a case study for its extreme and thus revelatory condition (Yin, 2014). The EPN connects two main mass railway stations (Mong Kok and Mong Kok East), a shopping mall (MOKO mall) and spans with an L-shape across main traffic arteries, MK Road and Sai Yee Street (Fig. 1). The access to this space was never restricted during the pandemic, owning to the EPN serving as pedestrian mobility connector. The functional design of the EPN is characterized by: overhead covering, railings, garbage bins, escalators and lifts (Fig. 2). 
Villani, C., et.al. / Asian Journal of Environment-Behaviour Studies (ajE-Bs), 5(17) Sep / Dec 2020 (pp.33-48)

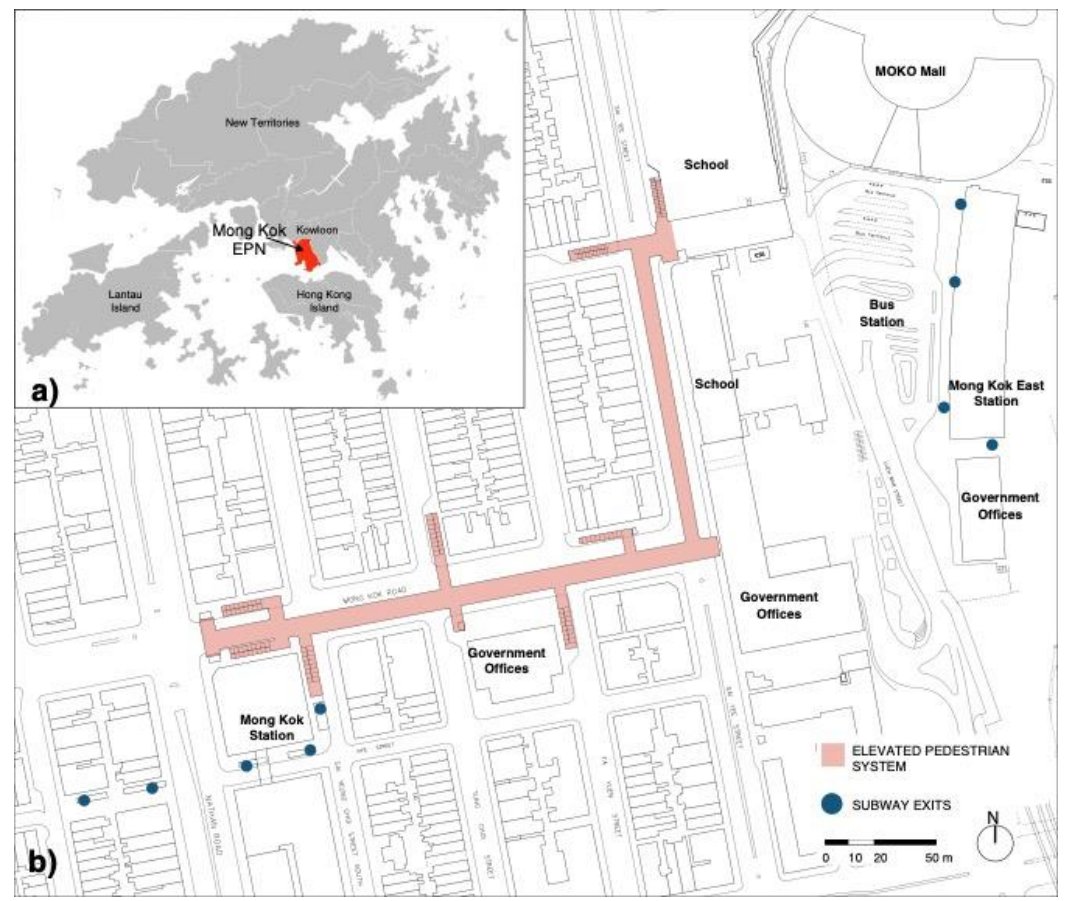

Fig. 1: a) Location of the EPN in Yau Tsim Mong District, Hong Kong B) Map of EPN (Source: The authors)

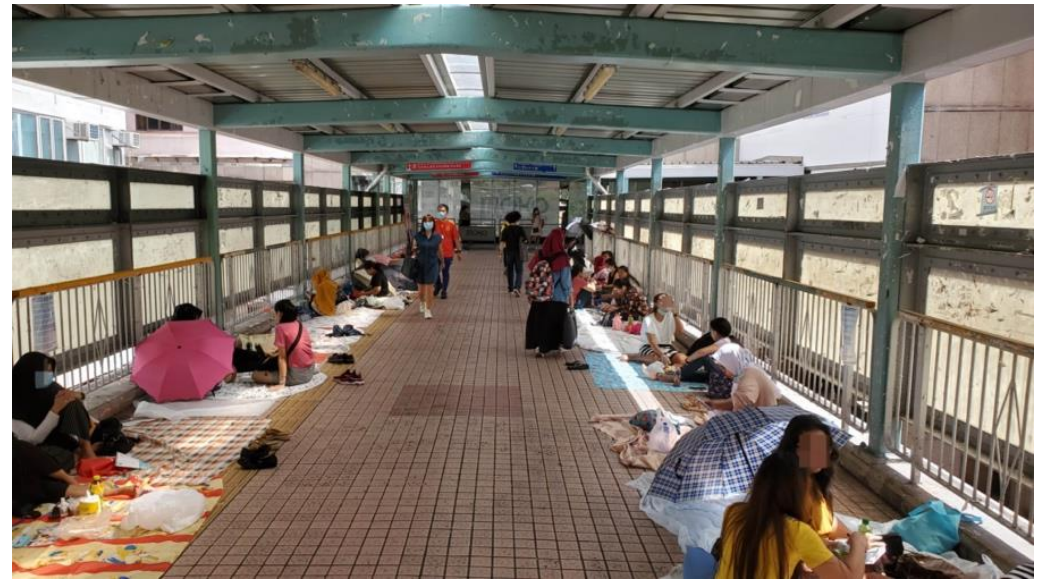

Fig. 2: The EPN in Mong Kok

(Source: The authors) 
Honey-Rosés et al. (2020) stress the crucial need for observational fieldwork to understand the impacts of COVID-19 on informal social interactions. Thus, environment-behaviour methods (Cheshmehzangi and Heath, 2017; Goličnik Marušic, 2016; Hanan, 2017; Tammikakul and Raksawin, 2019), as videography and behavioural mapping, were adopted to analyze spatio-temporal patterns of use and associate them with specific EPN spatial features during the post-outbreak period.

In order to compare the post-outbreak use of the EPN with pre-pandemic results, the data collection and analysis follows Villani and Talamini (2020). Stationary activities data were collected during three timeslots (morning, midday, afternoon) at the beginning of July 2020. The three observations were video-recorded as in Villani and Talamini (2020). After debriefing sessions aimed at categorizing the observed behaviours, the activities were recorded on a GIS platform (Tammikakul and Raksawin, 2019) and rendered through DotDistribution and Kernel Density maps. The behavioural data $(n=3068)$ were examined through geoprocessing and spatial analysis; descriptive statistics were reported in the findings' section.

The data reflect the occupancy during three periods in one weekend day. Intrinsic limitations of manual geo-plotting must be acknowledged. The objective is to identify postoutbreak changes in stationary patterns of use exist in the Hong Kong skywalks; this analysis does not imply causality.

\subsection{Results}

A total of 3068 stationary activities are visualized through the Dot Distribution Map (Fig. 2) to illustrate the quantity and density of people. The average stationary activities' number is 1022.7 (Table 1). Among them, the number of activities at midday is the largest (1190 observations), which is about $16 \%$ higher than the average activities' quantity.

\subsection{Temporal and activities patterns}

The average occupancy of the entire EPN area is 0.28 person $/ \mathrm{m}^{2}$, and the highest value occurs during midday $\left(0.33\right.$ person $\left./ \mathrm{m}^{2}\right)$. Through the classification of activity types (Table 2 ), detailed information can be obtained regarding the use of the EPN. Social activities $(60.0 \%)$ are the most common, followed by individual activities (34.3\%) and productionoriented activities (5.7\%). Among the social activities, chatting (50.6\%) is the most observed activity, while using the phone (16.1\%) accounts for the largest proportion of individual activities. MDWs tend to engage in hawking (3.4\%) -selling jewelry or snacksas production-oriented activities. Fig. 2 and Fig. 3 illustrates the daily rhythm distinguished by activities type. MDWs are more engaged in individual and production-oriented activities in the morning while these activities decrease at midday and keep steady from midday to afternoon. A reverse trend is observed for social activities that increase from morning to midday and are steady during the afternoon. 


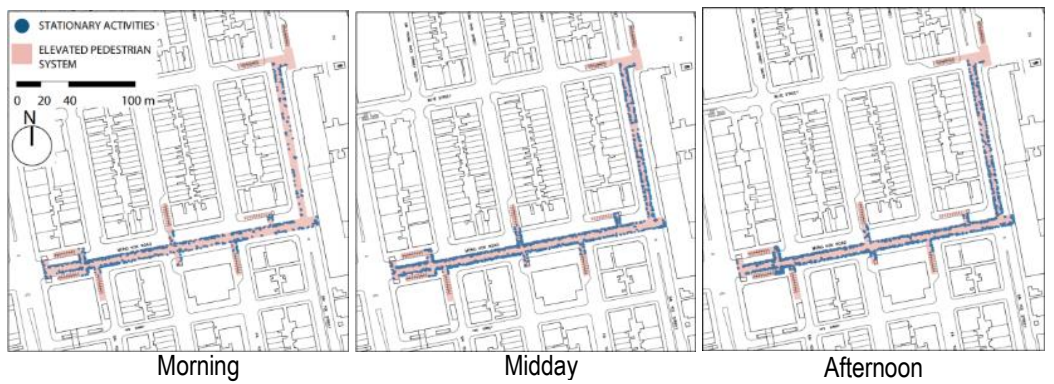

Fig. 3: a) Dot Distribution Map of stationary activities in the EPN (Source: The authors)

Table 1. Activities and density per observation period

\begin{tabular}{lll}
\hline Period & Observations & Density [person $/ \mathrm{m} 2]$ \\
\hline Morning & 705 & 0.19 \\
Midday & 1190 & 0.33 \\
Afternoon & 1173 & 0.32 \\
Average & $\mathbf{1 0 2 2 . 7}$ & $\mathbf{0 . 2 8}$ \\
\hline
\end{tabular}

(Source: The authors)

Table 2. Proportion of activities per observation period

\begin{tabular}{|c|c|c|c|c|c|c|c|c|}
\hline \multirow[t]{2}{*}{ Period } & \multicolumn{8}{|c|}{ Individual } \\
\hline & $\begin{array}{l}\text { Laying } \\
\text { down }\end{array}$ & $\begin{array}{c}\text { Standi } \\
\text { ng }\end{array}$ & Packing & $\begin{array}{l}\text { Self- } \\
\text { care }\end{array}$ & $\begin{array}{l}\text { Eating } \\
\text { (alone) }\end{array}$ & $\begin{array}{l}\text { Using } \\
\text { phone }\end{array}$ & $\begin{array}{c}\text { Smokin } \\
\mathrm{g}\end{array}$ & Crafting \\
\hline Morning & $2.1 \%$ & $5.5 \%$ & $7.4 \%$ & $1.8 \%$ & $5.7 \%$ & $13.1 \%$ & $0.9 \%$ & $0.1 \%$ \\
\hline Midday & $3.8 \%$ & $3.3 \%$ & $2.3 \%$ & $1.3 \%$ & $4.4 \%$ & $17.6 \%$ & $0.6 \%$ & $0.3 \%$ \\
\hline Afternoon & $5.6 \%$ & $3.8 \%$ & $2.5 \%$ & $0.7 \%$ & $2.4 \%$ & $17.8 \%$ & $0.6 \%$ & $0.1 \%$ \\
\hline Average & $3.8 \%$ & $4.2 \%$ & $4.0 \%$ & $1.2 \%$ & $4.1 \%$ & $16.1 \%$ & $0.7 \%$ & $0.2 \%$ \\
\hline Total & \multicolumn{8}{|c|}{$34.3 \%$} \\
\hline \multirow[t]{2}{*}{ Period } & \multicolumn{6}{|c|}{ Social } & \multicolumn{2}{|c|}{ Production oriented } \\
\hline & Chatting & $\begin{array}{c}\text { Prayin } \\
g\end{array}$ & $\begin{array}{l}\text { Taking } \\
\text { a Selfie }\end{array}$ & $\begin{array}{l}\text { Sharin } \\
\mathrm{g} \text { food }\end{array}$ & $\begin{array}{l}\text { Talking on } \\
\text { the phone }\end{array}$ & Give care & $\begin{array}{c}\text { Preparin } \\
\mathrm{g} \text { food }\end{array}$ & $\begin{array}{l}\text { Hawking (or } \\
\text { selling) }\end{array}$ \\
\hline Morning & $38.4 \%$ & $0.3 \%$ & $0.6 \%$ & $12.8 \%$ & $2.4 \%$ & $0.3 \%$ & $4.1 \%$ & $4.5 \%$ \\
\hline Midday & $55.4 \%$ & $0.1 \%$ & $0.3 \%$ & $4.8 \%$ & $1.8 \%$ & $0.3 \%$ & $1.5 \%$ & $2.6 \%$ \\
\hline Afternoon & $58.0 \%$ & $0.1 \%$ & $0.1 \%$ & $3.0 \%$ & $1.3 \%$ & $0.1 \%$ & $1.2 \%$ & $2.9 \%$ \\
\hline Average & $50.6 \%$ & $0.2 \%$ & $0.3 \%$ & $6.9 \%$ & $1.8 \%$ & $0.2 \%$ & $2.3 \%$ & $3.4 \%$ \\
\hline Total & \multicolumn{6}{|c|}{$60.0 \%$} & \multicolumn{2}{|c|}{$5.7 \%$} \\
\hline
\end{tabular}

(Source: The authors) 


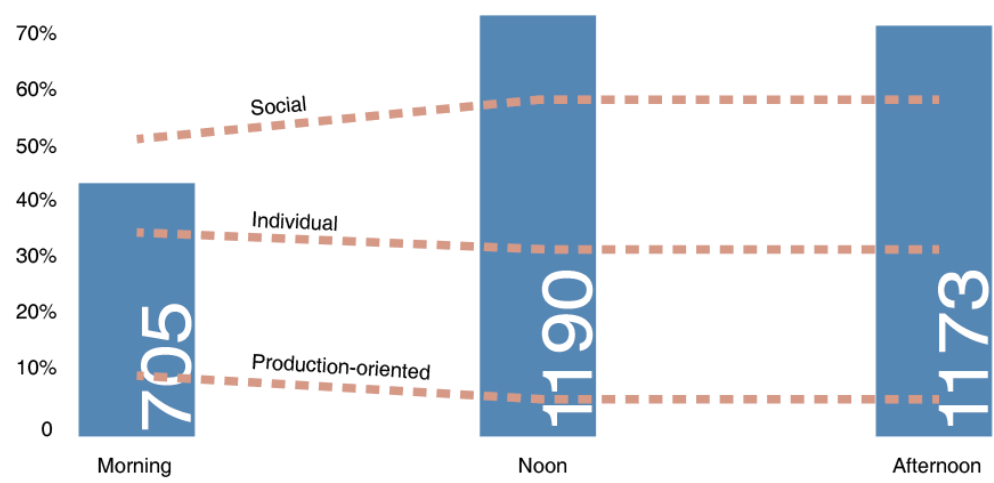

Fig. 4. Individual time-segments and corresponding activities type rhythm (Source: The authors)

\subsection{Location-related and activity-related and potentially hazardous contacts}

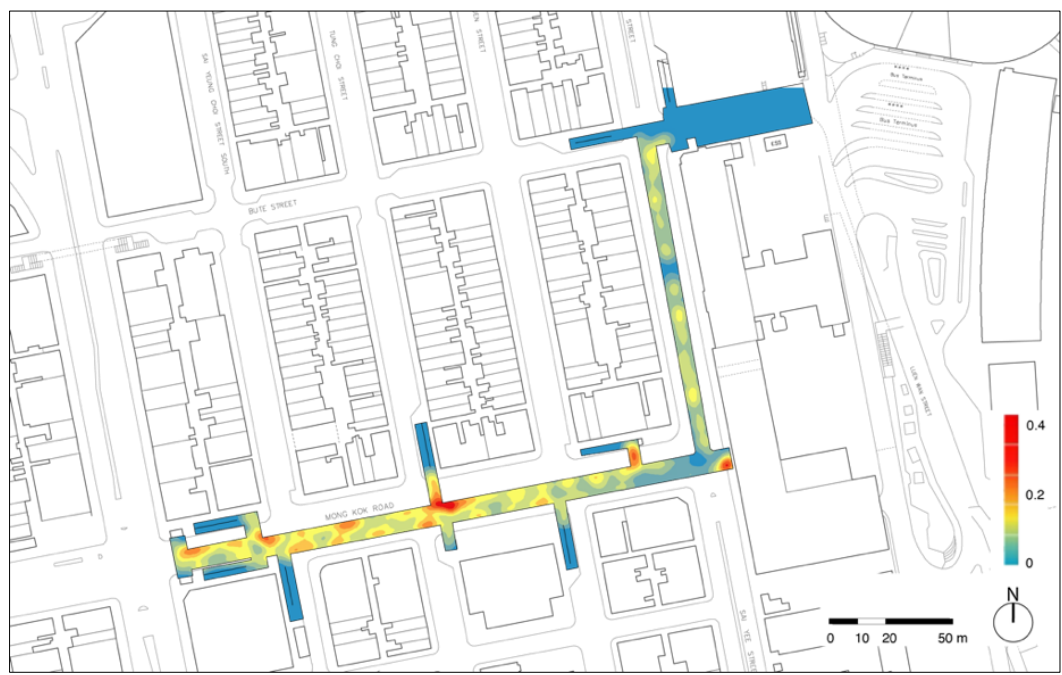

Fig. 5: Kernel Density Map of Stationary activities at midday in the EPN (Source: The authors)

The Kernel density map (Fig. 5) reveals that the density of the population is not equally distributed, but it is spatially concentrated near specific environmental features. The EPN area is divided into: part 1 (the widest segment of EPN), part 2, and the $2 \mathrm{~m}$ buffer from the railing line (Fig. 6). Besides, a 1-meter buffer from the production-oriented activities and the 
garbage bins is also analyzed. The average density of part $1\left(0.32\right.$ person $\left./ \mathrm{m}^{2}\right)$ is higher than the one of part $2\left(0.23\right.$ person $\left./ \mathrm{m}^{2}\right)$ (Table. 3$)$. Stationary activities cluster near the railing area $\left(0.63\right.$ person $\left./ \mathrm{m}^{2}\right)$ and tend to stay away from the garbage bins $\left(0.32\right.$ person $\left./ \mathrm{m}^{2}\right)$. Moreover, the density around production-oriented locations $\left(0.57\right.$ person $\left./ \mathrm{m}^{2}\right)$ is higher than the average activities' density (Table 3.). MDWs first occupy the EPN Part 1 in the morning $\left(0.25\right.$ person $\left./ \mathrm{m}^{2}\right)$, then populate Part 2 from noon.
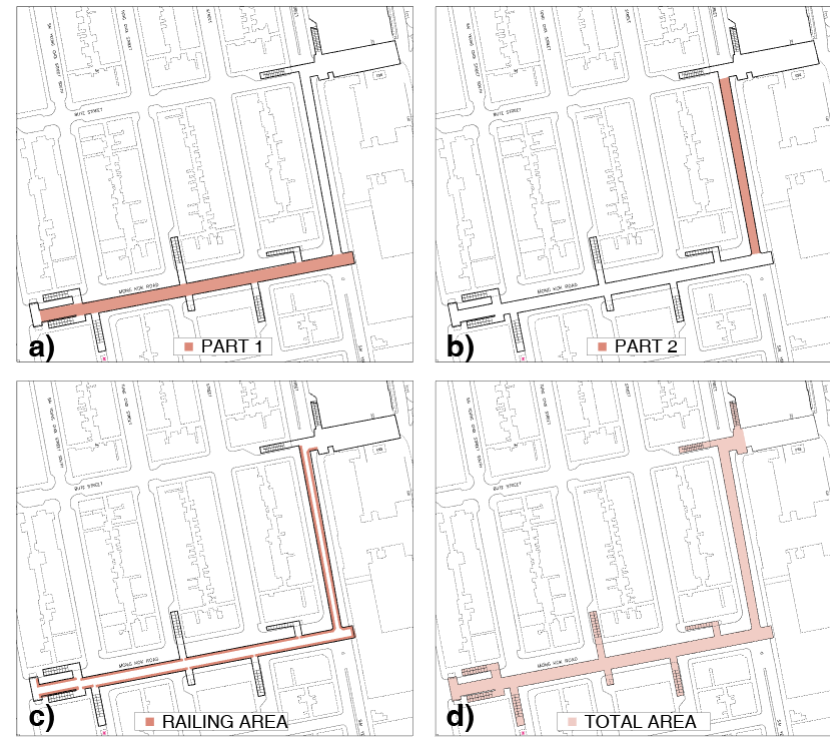

Fig. 6: a) the EPN part 1. b) The EPN part 2. c) The railing space (2 $\mathrm{m}$ offset) d) Total EPN area (Source: The authors)

Table 3. Activities' density per spatial feature

\begin{tabular}{lllllll}
\hline & Part 1 & Part 2 & Railing area & $\begin{array}{l}\text { Food } \\
\text { preparation } \\
\text { area }\end{array}$ & $\begin{array}{l}\text { Garbage bins } \\
\text { area }\end{array}$ & Total Area \\
\hline Morning & 0.25 & 0.09 & 0.42 & 0.51 & 0.21 & 0.19 \\
Noon & 0.36 & 0.28 & 0.73 & 0.61 & 0.43 & 0.33 \\
Afternoon & 0.35 & 0.31 & 0.73 & 0.58 & 0.32 & 0.32 \\
Average & $\mathbf{0 . 3 2}$ & $\mathbf{0 . 2 3}$ & $\mathbf{0 . 6 3}$ & $\mathbf{0 . 5 7}$ & $\mathbf{0 . 3 2}$ & $\mathbf{0 . 2 8}$ \\
\hline
\end{tabular}

(Source: The authors)

\subsection{Presence of protective measures, size and distance between groups of people}

During the COVID-19 period, the use of masks and precautions as hand hygiene or wearing disposable gloves are common measures to limit the risk of contracting and spreading of the virus (Table 4). In the EPN area, the proportion of stationary users wearing masks is $11 \%$. There are fewer stationary users wearing masks at noon (9.2\%). Overall MDWs 
wearing gloves are $7.4 \%$, nevertheless, it is observed that the use of gloves is related to food consumption activities: among the users who are eating (Table 5), on average, more than $48 \%$ are wearing gloves.

Table 4. The proportion of mask and precaution

\begin{tabular}{lll}
\hline Period & Mask & Precaution (glove) \\
\hline Morning & $11.9 \%$ & $13.3 \%$ \\
Midday & $9.2 \%$ & $4.6 \%$ \\
Afternoon & $11.9 \%$ & $4.2 \%$ \\
Average & $\mathbf{1 1 . 0 \%}$ & $\mathbf{7 . 4 \%}$ \\
\hline \multicolumn{3}{l}{}
\end{tabular}

Table 5. Use of gloves among people eating food

\begin{tabular}{llll}
\hline Period & Eating food & Wearing gloves & Proportion \\
\hline Morning & 130 & 76 & $58.5 \%$ \\
Noon & 109 & 37 & $33.9 \%$ \\
Afternoon & 63 & 33 & $52.4 \%$ \\
Average & $\mathbf{1 0 0 . 7}$ & $\mathbf{4 8 . 7}$ & $\mathbf{4 8 . 3 \%}$ \\
\hline \multicolumn{4}{c}{ (Source: The authors) }
\end{tabular}

Through geoprocessing and descriptive statistics, Table 6 shows the average size of the users' groups. Dividing the total number of people by the number of groups gives an average of approximately 2.24 people in each group. By using proximity analysis to calculate the distance between all activities-points and their closest neighbor, the average distance of $0.83 \mathrm{~m}$ can be obtained (Table 7). Noticeably, at the time of data collection, the maximum group size allowed by the government's guidelines was 50 people, and the recommended safe distance among people was at least $1 \mathrm{~m}$. In the morning, owing to a lower occupation density, the average group size is smaller (1.98 people), and people are farther away (0.96 $\mathrm{m}$ on average).

Table 6. Group size

\begin{tabular}{llll}
\hline Period & $\begin{array}{l}\text { Number of } \\
\text { people }\end{array}$ & groups & $\begin{array}{l}\text { People per } \\
\text { group }\end{array}$ \\
\hline Morning & 705 & 356 & 1.98 \\
Noon & 1190 & 507 & 2.35 \\
Afternoon & 1173 & 489 & 2.40 \\
Average & $\mathbf{1 0 2 2 . 7}$ & $\mathbf{4 5 0 . 7}$ & $\mathbf{2 . 2 4}$ \\
\hline \multicolumn{5}{c}{ (Source: The authors) }
\end{tabular}

Table 7. Distance between people

\begin{tabular}{llll}
\hline Period & Minimum $(\mathrm{m})$ & Maximum $(\mathrm{m})$ & Average $(\mathrm{m})$ \\
\hline Morning & 0.31 & 6.24 & 0.96 \\
Noon & 0.25 & 4.02 & 0.77 \\
Afternoon & 0.34 & 3.82 & 0.77 \\
Average & $\mathbf{0 . 3 0}$ & $\mathbf{4 . 6 9}$ & $\mathbf{0 . 8 3}$ \\
\hline \multicolumn{3}{c}{ (Source: The authors) }
\end{tabular}




\subsection{Discussion}

Overall, we observed changes in activities-type spatial and temporal patterns and possible surface contact during SD relaxation, compared to the pre-pandemic situation. PM use and distance between groups were also reported. We estimated an overall decrease in the MDWs activities compared to the pre-pandemic observations reported in Villani and Talamini (2020), collected during afternoon time. The following comparative observations are based on the afternoon observations reported in the findings section.

The afternoon stationary activities number (1173) and activities density $(0.32$ person $/ \mathrm{m}^{2}$ ) decreased by $20.6 \%$ and $22 \%$ respectively in the SD relaxation phase compared to pre-pandemic findings in the same EPN (Villani and Talamini, 2020). Compared with the pre-pandemic period, chatting ( $58 \%$, total $680 \mathrm{MDWs}$ ) during the postoutbreak period is drastically lower than before pandemic (87 \%, average $1292.3 \mathrm{MDWs}$ ), while the percentage of sharing-food activity slightly increased from the pre-pandemic average of $31 \mathrm{MDWs}(2 \%)$ to 35 users, $3 \%$. At the same time, individual activities increased from $8 \%$ (average $108.4 \mathrm{MDWs}$ ) during pre-pandemic to $33.4 \%$ (total 392) during the pandemic. In particular, we observed a higher percentage of migrants laying down relaxing alone during pandemic (5.63\%). This may indicate that the preference for activities shifted from more informal group conversation time (pre-pandemic) to limited individual leisure activities that do not involve gathering but resting activities. MDWs resting in public space have been observed in the past, as well as in other settings in Hong Kong (Chu and Catalan, 2020; Law, 2002; Villani and Talamini, 2021) and in other Asian cities. This considerable shift from social to individual, resting activities (sleeping and laying down on the floor) in public space is related to SD measures and might indicate an underlying increase in the MDWs' stress and work-related fatigue during the pandemic.

Patterns of spatial occupancy changed, with the slightly lower occupation of spaces that may potentially lead to infected surface contact as railings (24\% density decrease). Additionally, density around informal food-production -freshly made meals- $(0.58$ person $/ \mathrm{m}^{2}$ ) dropped by $53.6 \%$ compared to pre-pandemic. These patterns may indicate MDWs preference to avoid possible surface contact or food or money exchange, despite the reported importance of food as a gathering factor for migrant populations in the PS of high-density Asia (Zordan et al., 2019). Masks were not widely used, and fewer stationary users are wearing these at noon (9.2\%), this may be due to the higher temperature and concurrent eating activities. However, current research indicates that even in lower transmission settings, as PSs, the use of face masks may contribute to reducing transmission (Maclntyre and Hasanain, 2020). The public are usually limiting the period during which they wear masks to the duration of essential activities (e.g. buying grocery) in PS (Szepietowski et al., 2020). MDWs tend to gather in PS for a prolonged time while they perform non-essential activities; thus, the use of face mask might become challenging. Lower use of masks may also indicate that MDWs face barriers in obtaining this protective measure (Liem et al., 2020). Regarding the proportion of users wearing gloves, we need to note that this practice was already observed before the pandemic and is linked to the cultural habits of eating food (Constable, 2009). Even though almost half of MDWs wear 
gloves to eat, this habit may not be connected to protective measures' implementation. Finally, a significant change was observed in the drop in the number of people per group (less than 3), while before the pandemic this number was observed to be around 6-8 people. This drop might indicate an ongoing trend in limiting and reducing large gathering groups even during SD relaxation when larger groups were allowed. MDWs tend to gather with friends or family from the same region or sharing the same language (Law, 2002), a drop in the group size might lead to fewer social interactions and exchanges. The significant number of MDWs using a smartphone may indicate an increase in online social contact instead of meeting through physical presence.

All in all, the decrease in the number of users (about $20 \%$, from 1476.5 average to 1173) and density of activities, the shift from social to individual resting activities, the decrease in density at informal food-production and shrinking size of gathering groups indicate that COVID-19 pandemic had an impact on the use of public space in the SD relaxation period.

\subsection{Conclusion}

Gathering and socializing in large groups in PS was commonly found among MDWs in prepandemic conditions and deemed crucial for mental health, well-being and socio-economic resilience of this deprived social group. During the post-outbreak period, the effects of the observed drop in stationary -particularly social- activities may lead to alarming well-being repercussions, thus need to be further researched. Specifically, the exchange of job or welfare-related information and the crucial support networks (Chu and Catalan, 2020) that rely on these social gatherings may be impacted. In light of the long-term use that MDWs established in this and other similar spaces (Villani and Talamini, 2021) the post-outbreak decrease in use might also lead to public space and placemaking changes. The findings shed new light on the necessity of considering the peculiar needs of vulnerable groups in post-pandemic policymaking response. In the past, pandemics have resulted in scarce post-pandemic actions aiming at addressing the needs of low-income groups (Sharifi and Khavarian-Garmsir, 2020).

Nevertheless, in the aftermath of the crisis, cities may need some critical challenges, as spatial justice, to be addressed in the path towards an inclusive planning agenda for low-income groups (Jon, 2020). New directions for research may include investigations on the use of other PS, interviews with MDWs' and extension of the observation days and location to better capture the PS use and selection choice during the pandemic evolution. Further analysis may also associate environmental factors to stress levels (Jiang et al., 2019).

\section{Acknowledgement}

This research was financially supported by a grant from the City University of Hong Kong (Project No. 6000645). We would like to thank Zhang Junlin for his assistance during the 
data collection.

\section{Article Contribution to Related Field of Study}

Empirical evidence of a change in behavioral patterns associated with the COVID-19 impact on social norms is as follows:

1) Overall decrease of around $20 \%$ in stationary activities number and decrease of group size compared to pre-pandemic.

2) Increase in individual activities, particularly resting and using the smartphone.

3) Patterns of spatial occupancy changed with lower density associated with railings and informal food-production area.

4) This study is the first environment-behaviour study on migrant domestic workers' use of public space during social distancing relaxation.

\section{References}

Anguelovski I, Brand AL, Connolly JJT, et al. (2020) Expanding the Boundaries of Justice in Urban Greening Scholarship: Toward an Emancipatory, Antisubordination, Intersectional, and Relational Approach. Annals of the American Association of Geographers 110(6). Taylor and Francis Ltd.: 1743-1769. DOI: 10.1080/24694452.2020.1740579.

Castillo R and Amoah PA (2020) Africans in post-COVID-19 pandemic China: is there a future for China's 'new minority'? Asian Ethnicity 21(4). Routledge: 560-565. DOI: 10.1080/14631369.2020.1773760.

Cheshmehzangi A and Heath T (2017) Effects of Temporary Markets on Spatial Inter-relations: A behavioural analysis of a public realm in the UK. Journal of ASIAN Behavioural Studies 2(3). e-IPH Ltd.: 41. DOI: 10.21834/jabs.v2i3.190.

Choudhari R (2020) COVID 19 pandemic: Mental health challenges of internal migrant workers of India. Asian Journal of Psychiatry 54. Elsevier B.V.: 102254. DOI: 10.1016/j.ajp.2020.102254.

Chu C and Catalan M (2020) Beyond the Sunday Spectacle: Foreign Domestic Workers and Emergent Civic Urbanisms in Hong Kong. In: Cho IS, Kriznik B, and Hou J (eds) Emerging Civic Urbanisms in East Asia. Amsterdam: Amsterdam University Press.

Constable N (2009) Migrant workers and the many states of protest in Hong Kong. Critical Asian Studies 41(1): 143-164. DOI: 10.1080/14672710802631202.

Eikenberry SE, Mancuso M, Iboi E, et al. (2020) To mask or not to mask: Modeling the potential for face mask use by the general public to curtail the COVID-19 pandemic. Infectious Disease Modelling 5. KeAi Communications Co.: 293-308. DOI: 10.1016/j.idm.2020.04.001.

Elsheshtawy Y (2020) Urban enclaves and transient cosmopolitanism: Scenes from Abu Dhabi and Dubai. City. Routledge. DOI: 10.1080/13604813.2020.1843279.

Goličnik Marušic B (2016) Discrepancy between likely and actual occupancies of urban outdoor places. Urban Forestry and Urban Greening 18: 151-162. DOI: 10.1016/j.ufug.2016.06.001.

Hanan H (2017) Every Day Practices and Experiential Urban Space. Asian Journal of Environment-Behaviour 
Villani, C., et.al. / Asian Journal of Environment-Behaviour Studies (ajE-Bs), 5(17) Sep / Dec 2020 (pp.33-48)

Studies 2(5). e-IPH Ltd.: 27. DOI: 10.21834/aje-bs.v2i5.220.

HKSAR (2020) Government announces latest disease prevention measures. 30 June. Hong Kong.

Honey-Rosés J, Anguelovski I, Chireh VK, et al. (2020) The impact of COVID-19 on public space: an early review of the emerging questions - design, perceptions and inequities. Cities \& Health. Informa UK Limited: 1-17. DOI: $10.1080 / 23748834.2020 .1780074$.

Jiang B, Wang H, Larsen L, et al. (2019) Quality of sweatshop factory outdoor environments matters for workers' stress and anxiety: A participatory smartphone-photography survey. Journal of Environmental Psychology 65. Academic Press: 101336. DOI: 10.1016/j.jenvp.2019.101336.

Jon I (2020) A manifesto for planning after the coronavirus: Towards planning of care. Planning Theory 19(3). SAGE Publications Ltd: 329-345. DOI: 10.1177/1473095220931272.

Koh D (2020) Migrant workers and COVID-19. Occup Environ Med 77: 634-636. DOI: 10.1136/oemed-2020106626.

Lai KY, Webster C, Kumari S, et al. (2020) The nature of cities and the Covid-19 pandemic. Current Opinion in Environmental Sustainability. DOI: 10.1016/j.cosust.2020.08.008.

Law L (2002) Defying Disappearance: Cosmopolitan Public Spaces in Hong Kong. Urban Studies 39(9): 16251645. DOI: $10.1080 / 00420980220151691$.

Liem A, Wang C, Wariyanti Y, et al. (2020) The neglected health of international migrant workers in the COVID19 epidemic. The Lancet Psychiatry 7(4). Elsevier Ltd: e20. DOI: 10.1016/S2215-0366(20)30076-6.

Maclntyre CR and Hasanain SJ (2020) Community universal face mask use during the COVID 19 pandemic-from households to travellers and public spaces. Journal of Travel Medicine 27(3): 1-3. DOI: 10.1093/jtm/taaa056.

Martinez R and Masron IN (2020) Jakarta: A city of cities. Cities 106. Elsevier Ltd: 102868. DOI: 10.1016/j.cities.2020.102868.

Nobajas A, Casas JG i, Agusti DP i, et al. (2020) Lack of sufficient public space can limit the effectiveness of COVID-19's social distancing measures. medRxiv (April): 2020.06.07.20124982. DOl: 10.1101/2020.06.07.20124982.

Ostertag E (2016) Transitory community hubs: How temporary migration transforms a neighbourhood in Singapore. City 20(1). Taylor \& Francis: 116-129. DOI: 10.1080/13604813.2015.1096058.

Pouso S, Borja Á, Fleming LE, et al. (2020) Contact with blue-green spaces during the COVID-19 pandemic lockdown beneficial for mental health. Science of The Total Environment (xxxx). Elsevier B.V.: 143984. DOI: 10.1016/j.scitotenv.2020.143984.

Salama AM (2020) Coronavirus questions that will not go away: interrogating urban and socio-spatial implications of COVID-19 measures. Emerald Open Research 2: 14. DOI: 10.35241/emeraldopenres.13561.1.

Samuelsson K, Barthel S, Colding J, et al. (2020) Urban nature as a source of resilience during social distancing amidst the coronavirus pandemic. OSF Preprints. DOI: 10.31219/osf.io/3wx5a.

Sharifi A and Khavarian-Garmsir AR (2020) The COVID-19 pandemic: Impacts on cities and major lessons for urban planning, design, and management. Science of the Total Environment. DOI: 10.1016/j.scitotenv.2020.142391. 
Sun R, Balabanova A, Bajada CJ, et al. (2020) Psychological wellbeing during the global COVID-19 outbreak. PsyArXiv. DOI: 10.31234/osf.io/r7xaz.

Szepietowski JC, Matusiak $Ł$, Szepietowska M, et al. (2020) Face mask-induced itch: A self-questionnaire study of 2,315 responders during the COVID-19 pandemic. Acta Dermato-Venereologica 100(10). Medical Journals/Acta D-V: 1-5. DOI: 10.2340/00015555-3536.

Talamini G and Pires Ferreira D (2019) An informal transportation as a feeder of the rapid transit system. Spatial analysis of the e-bike taxi service in Shenzhen, China. Transportation Research Interdisciplinary Perspectives 1. Elsevier Ltd: 100002. DOI: 10.1016/j.trip.2019.100002.

Tammikakul P and Raksawin K (2019) The Pattern of Activity Analysis by GIS in Chiang Mai Public Plaza, Thailand. Asian Journal of Environment-Behaviour Studies 4(13). e-IPH Ltd.: 30. DOI: 10.21834/aje-bs.v4i13.346.

Villani C and Talamini G (2019) Patterns of Stationary Activities in the Elevated Pedestrian Networks of High Density Asian Cities: The case of Mong Kok, Hong Kong. Environment-Behaviour Proceedings Journal 4(12). eInternational Publishing House. DOI: 10.21834/e-bpj.v4i12.1905.

Villani C and Talamini G (2020) Socialising on a Skywalk: How Hong Kong's Elevated Walkways Become Public Open Spaces. Asian Journal of Environment-Behaviour Studies 5(15): 57-72. DOI: 10.21834/aje-bs.v5i15.361.

Villani C and Talamini G (2021) Pedestrianised streets in the global neoliberal city: A battleground between hegemonic strategies of commodification and informal tactics of commoning. Cities 108: 102983. DOI: 10.1016/j.cities.2020.102983.

Villani C, Zordan M, Talamini G, et al. (2019) Temporarily Pedestrianized Street in Hong Kong: Governmental Strategy of Implementation and Tactics of Appropriation by Foreign Domestic Workers. In: Proceedings of the AESOP 2019 Congress Book of Papers, Venice, 2019, p. 2559. The AESOP 2019 Congress.

Wade L (2020) An unequal blow. Science 368(6492). American Association for the Advancement of Science: 700-703. DOI: $10.1126 /$ science.368.6492.700.

Wang C, Pan R, Wan X, et al. (2020) Immediate psychological responses and associated factors during the initial stage of the 2019 coronavirus disease (COVID-19) epidemic among the general population in China. International Journal of Environmental Research and Public Health 17(5). MDPI AG: 1729. DOI: 10.3390/ijerph17051729.

Wang L, Tosi MC, Zordan M, et al. (2018) Walkable Cities in High Density China Livable, Healthy and Sustainable (C Yuaned. ). Shanghai: Tongji University Press.

Wang W (2020) Everyday practice in the high density, volumetric Hong Kong: Ambiguity, intensity and life between interfaces. Cities 96. Elsevier Ltd: 102462. DOI: 10.1016/j.cities.2019.102462.

Wray A, Fleming J and Gilliland J (2020) The public realm during public health emergencies: exploring local level responses to the COVID-19 pandemic. Cities \& Health: 1-4. DOI: $10.1080 / 23748834.2020 .1790260$.

Yin RK (2014) Case Study Research: Design and Methods. SAGE Publications.

Zhang J (2020) City \& Society Divided in a connected world: Reflections on COVID 19 from Hong Kong. DOI: $10.1111 /$ ciso.12264.

Zordan M, Talamini G and Villani C (2019) The Association between Ground Floor Features and Public Open Space Face-To-Face Interactions: Evidence from Nantou Village, Shenzhen. International Journal of 
Villani, C., et.al. / Asian Journal of Environment-Behaviour Studies (ajE-Bs), 5(17) Sep / Dec 2020 (pp.33-48)

Environmental Research and Public Health 16(24). Multidisciplinary Digital Publishing Institute: 4934. DOI: 10.3390/ijerph16244934. 